\title{
FORMACIÓN PARA LA SANTIDAD. TESTIMONIOS Y CASOS EJEMPLARES EN EL OPUS DEI ${ }^{12}$
}

\author{
Maria Bargo ${ }^{3}$
}

\begin{abstract}
Resumen: Este artículo explora la función formativa que los casos ejemplares tienen dentro de la Prelatura Personal del Opus Dei. Para ello repasa los procesos de canonización de la Obra y su importancia para validar el carisma e indaga sobre exposiciones testimoniales en instancias dirigidas a mujeres caritativas y niñas o jóvenes que participan de acciones solidarias en una ONG ligada a la Prelatura. El trabajo se compone tanto de la revisión de fuentes oficiales del Opus Dei como de la observación participante en las actividades mencionadas. La perspectiva etnográfica permite comprender el afán de formar integralmente a quienes asisten a dichas instancias mediante las exposiciones. Así, tanto los ejemplos "oficiales" propios de la Obra como los testimonios expuestos en las iniciativas descritas permiten formar a las niñas y jóvenes voluntarias o a las mujeres caritativas ofreciendo modelos imitables que demuestran la viabilidad de la pospuesta de santidad del Opus Dei: desempeñarse adecuadamente en las tareas cotidianas y adquirir habilidades para desenvolverse correctamente en sus ocupaciones ordinarias futuras que son vía propicia para la santificación propia y del entorno.
\end{abstract}

Palabras clave: Opus Dei; Santidad; Formación; Testimonio.

\section{FORMATION FOR SANCTITY. TESTIMONIES AND ROLE MODELS IN THE OPUS DEI}

\begin{abstract}
This paper analyzes the formative character that role models have at the Personal Prelature of Opus Dei. Therefore, it outlines the canonization processes

1 Como citar: BARGO, María. Formación para la santidad. Testimonios y casos ejemplares en el Opus Dei. Debates do NER, Porto Alegre, ano 21, n. 40, p. 415-446, 2021.

2 Este artículo está basado en la investigación que realicé durante mi doctorado. Parte de los registros de campo se trabajan con mayor profundidad en mi tesis relativa a los sentidos que el Opus Dei otorga a su intervención en torno a la pobreza en Argentina.

3 Doutoranda em Antropologia pelo Instituto de altos estudios sociales da Universidad Nacional de San Martin e pesquisadora no Consejo Nacional de Investigaciones Científicas y Técnicas, Argentina. E-mail: merybargo@gmail.com. ORCID: https:/orcid.org/0000-0001-9485-4282.
\end{abstract}

Debates do NER, Porto Alegre, ANo 2I, N. 4O, P. 4I 5-446, Ago./DeZ. 202 I 
that Opus Dei has and its importance to validate its carisma and explores the role of testimonies at activities offered to charitable women and girls or teens that take part of an ONG link to the Prelature. This research implied sources revision as well as participant observation in several activities. The ethnographic perspective allows us to further understand the/ir formative character of those activities through the expositions. Thus, each "official" Opus Dei example and testimony exposed in the described activities instruct all volunteer or charitable women and girls that get involved in them by showing the viability of the Opus Dei sanctity proposal: the properly develop in their daily affairs and learning diverse knowledge for future occupations which are the suitable path to sanctify themselves and others.

Keywords: Opus Dei, Sanctity; Formation, Testimony.

\section{INTRODUCCIÓN}

Además del propio panteón de seres poderosos (Siervos de Dios, Beatos y Santos), el Opus Dei presenta testimonios de casos ejemplares en diversas instancias que permiten concebir la oferta que su carisma ${ }^{4}$ - también denominado "espíritu" - indica como viable. Específicamente, su "espíritu" dicta que todas las personas podrían alcanzar la santidad por medio del trabajo y de las "circunstancias ordinarias" de la vida5. Según señalan Dias Duarte y Dullo en cuanto a la lógica testimonial, el sentimiento de legitimidad asociado al mismo se funda en la demostración de que existe una "búsqueda de una obediencia escrupulosa a las órdenes de Dios” (2016, p. 17). En el caso al que refiero, la selección y credibilidad otorgada a los ejemplos expuesto responde al respeto de la vía para la santificación propuesta por el grupo desde "el lugar donde toque". En esta dirección, Reinhardt (2016)

4 Las órdenes, congregaciones, movimientos eclesiales o prelaturas (diferentes formas de integrar la Iglesia católica), poseen "carismas" o "espíritus" que las caracterizan y diferencian de otros grupos, operando como sello identitario distintivo.

5 Las órdenes, congregaciones, movimientos eclesiales o prelaturas (diferentes formas de integrar la Iglesia católica), poseen "carismas" o "espíritus" que las caracterizan y diferencian de otros grupos.

Debates do NER, Porto Alegre, Ano 2 I, N. 40, P. 4I 5-446, Ago./Dez. 202 I 
comprende estas instancias como experiencias de transmisión del carisma grupal que alcanzan el estatus de método.

\section{ACCESO Y PERMANENCIA EN CAMPO}

El Opus Dei es la única "Prelatura Personal”" de la Iglesia Católica. Su denominación proviene del latín y significa "Obra de Dios”, por lo que muchos de sus integrantes la llaman cariñosamente "la Obra". Fundado por el sacerdote español Josemaría Escrivá de Balaguer en 1928, obtuvo la aprobación pontificia en 1948 y fue en 1982 que adoptó la condición jurídica que actualmente presenta.

En el 2015 comencé con mis primeras aproximaciones para conocer algunas cuestiones específicas sobre la organización e historia del Opus Dei. Asimismo, pretendía obtener información básica sobre las iniciativas solidarias que la Prelatura ofrece, impulsa o acompaña en la Ciudad de Buenos Aires, el conurbano bonaerense y parte de la provincia para realizar observación participante en ellas. Las exploraciones empíricas en estos espacios me servirían para entender sus modos de intervención social. Mis primeras incursiones consistieron en encuentros con familiares, amigos y conocidos vinculados a la Obra para introducirme al grupo e informarme sobre su funcionamiento, su estructura y las acciones que emprendían ${ }^{7}$.

6 Esta figura del derecho canónico significa que su jurisdicción, en vez de ser territorial, está a cargo del Prelado (único cargo vitalicio), quien gobierna en colaboración con un consejo de mujeres - denominado Asesoría Central - y uno de hombres - llamado Consejo General.

7 Apelar a mi vida en Bella Vista, localidad donde pasé casi toda mi infancia, me sirvió para comenzar la investigación. En tal sentido, tanto el barrio como mi historia personal me permitieron recurrir a apellidos de conocidos - de familias católicas de la zona, de familias con "doble apellido" y de otras que componen la "guía azul" (guía social que dispone información de contacto básica sobre familias que pagan una "contribución" por integrar dicho listado. Parte de mi familia materna - yo incluida - está registrada en la misma). Así, mi cercanía a la "clase alta” (Gessaghi, 2015) me ayudó a operar en

Debates do NER, Porto Alegre, ANo 2 I, N. 4O, P. 4I 5-446, Ago./DeZ. 202 I 
Tras las charlas introductorias, algunas entrevistas iniciáticas y la participación en un evento de recaudación de fondos para una de las actividades solidarias vinculadas a la Prelatura, decidí empezar el trabajo de campo en el año 2016. Con este propósito, conseguí una reunión con quienes estaban a cargo de la Oficina de Comunicación del Opus Dei ubicada en un edificio histórico sobre Diagonal Norte esquina Florida, el cual es la única propiedad de la Obra en Argentina. Días después, una de las encargadas me envió un listado de nombres, direcciones de email, celulares y actividades. Cada uno me había sido recomendado y correspondía a alguna de las labores sociales que los miembros de la Prelatura llevaban a cabo. Siguiendo estas sugerencias me contacté con ellos por email en primer lugar y luego de manera telefónica con quienes respondieron. Al presentarles mi trabajo de investigación con algo más de detalle, los informantes me sugirieron numerosas acciones que, aunque no todas apuntaban necesariamente a gente desfavorecida económicamente, consideraban labores solidarias que también podían formar parte del estudio. Así me involucré de modo estable - semanal o quincenal - en la mayoría de éstas. Algunas funcionaban ocasionalmente, se destinaban a hombres, acontecían en el interior de la Provincia de Buenos Aires o se encontraban en proceso de cambio o aun de cierre por lo cual suponían que mi presencia podía interferir en su desarrollo. En otras, las responsables decidieron que debía esperar la respuesta de una referente del Opus Dei como condición necesaria para darme acceso.

estos contextos y entender qué recursos invocar en cada oportunidad. Sin duda, me fue de gran ayuda el haber sido socializada en el catolicismo e incluso haber frecuentado ámbitos de sociabilidad católicos (como grupos parroquiales o la participación en retiros espirituales, entre otras cuestiones). Por ello, contaba con algunos conocimientos doctrinales o rituales que pude poner en juego. Además, el haber realizado trabajo de campo con sectores tradicionalistas católicos me sirvió para saber cómo moverme. También envié una carta de presentación a los representantes de iniciativas sociales con quienes me contactaron e incluí una carta del IDAES como aval académico.

Debates do NER, Porto Alegre, ano 2 I, N. 4O, P. 4I 5-446, Ago./Dez. 202 I 


\section{Composición y ORganización del OPUS DeI ${ }^{8}$}

Existen diferentes maneras de formar parte de la Prelatura del Opus Dei, en tanto su "carisma" ofrecería la posibilidad de alcanzar la santidad a todos mediante las ocupaciones cotidianas y su "correcta" realización. En tal sentido, estas últimas varían de acuerdo al género y las condiciones de vida de cada individuo.

Entre sus miembros están los numerarios (que pueden ser clérigos o laicos) y las numerarias, que son quienes poseen mayor disponibilidad para responder a las necesidades del Prelado, viven en comunidad separados por género en celibato apostólico y no toman ningún voto sino que "practican todas las virtudes" 9 . Se encargan, a su vez, de dirigir los apostolados y de la formación de los demás fieles del Opus Dei - o a quienes deseen participar de las charlas - pudiendo ser trasladados con este fin ${ }^{10}$. Quienes se dediquen al gobierno o formación en alguna sede particular residen allí mismo. Al momento de pedir la admisión a la Obra, los numerarios deben haber obtenido un título académico civil o profesional equivalente o demostrar posibilidades de adquirirlo tras ser admitidos. Para las mujeres, en cambio, esto es opcional. Las numerarias, específicamente, atienden los centros de la Prelatura - incluso los masculinos- aunque viven en sedes propias.

8 La información fue conformada a partir de relatos de miembros de la Obra y la revisión de los estatutos, es decir: la "norma jurídica fundamental por la que se rige esta Prelatura". Ver más en: https://opusdei.org/es-ar/article/estatutos-del-opus-dei/. Acceso en: 29 oct. 2019.

9 Entrevista realizada a una numeraria en el centro La Loma, Bella Vista el viernes 8 de mayo de 2015. También conocidas como "virtudes teologales" son aquellas que permiten orientar la acción humana a Dios y se diferencian de los votos canónicos, siendo que éstos corresponden únicamente a los miembros religiosos de la Iglesia y no así a los seglares.

10 Según Thumala Olave, siendo que personas externas a la Obra pueden participar de los medios de formación, "uno de los deberes de los numerarios es identificar miembros potenciales e invitarlos a los eventos formativos" (2010, p. 19, traducción nuestra).

Debates do NER, Porto Alegre, ANo 2 I, N. 4O, P. 4I 5-446, Ago./DeZ. 202 I 
Por su parte, las numerarias auxiliares viven en comunidad y celibato apostólico en las Administraciones (con la misma disponibilidad que las numerarias); son mujeres y se dedican únicamente a labores domésticas en los centros del Opus Dei. Una de las numerarias que administra la casa de retiros "La Chacra" me explicó que las auxiliares son "como las mamás", porque "hacen al espíritu de familia en todos los centros de la Obra". En este caso, me comentó, su vocación al Opus Dei coincidiría con su vocación profesional, es decir que su vocación espiritual es también su trabajo.

$\mathrm{Al}$ igual que los anteriores, las agregadas y agregados son laicos célibes y poseen disponibilidad a las solicitudes del Prelado. Sin embargo, no viven en centros de la Obra como los anteriores sino en sus propias casas, por "su carácter o porque deben cuidar a algún familiar" 11 . Su posibilidad de dedicación al apostolado y formación del resto de los fieles se ve sujeta a ello. Poseen, de todas maneras, los mismos deberes y obligaciones que los numerarios y numerarias.

Por otro lado, los y las supernumerarias ${ }^{12}$ son laicos célibes o casados con igual vocación divina que el resto de los miembros de la Obra. Éstos participan de los apostolados del Opus Dei en la medida que los mismos sean compatibles con sus obligaciones familiares, profesionales y sociales. Además de buscar la santidad a través de los apostolados y actividades laborales, deben hacerlo en su hogar. En caso de cumplir con los requisitos pueden tornarse numerarios o agregados posteriormente. A su vez, quienes solicitan la admisión como numerarios y agregados, son aceptados como supernumerarios hasta que su pedido sea considerado.

Una categoría novedosa que abrió la propuesta a aquellos que no necesariamente son católicos (y que pueden tener otra orientación religiosa o no ser creyentes) es la de "cooperadores”. Éstos pueden colaborar con oración,

${ }^{11}$ Entrevista realizada al sacerdote en el Colegio del Buen Consejo de Barracas el lunes 5 de septiembre de 2016.

12 Thumala Olave (2010) detalla que éstos conforman la mayoría del Opus Dei, representando cerca de un $70 \%$ de los miembros. 
donaciones o trabajo en las labores apostólicas de la Obra y recibir formación espiritual de así desearlo. Asimismo, los fieles de la Prelatura ofrecen oraciones y actos de mortificación por ellos "para conseguirles la misericordia divina, por intercesión de la Santísima Virgen, la luz indefectible de la fe y para atraerles de forma suave y eficaz a las costumbres cristianas" (Traducción de los Estatutos del Opus Dei) ${ }^{13}$.

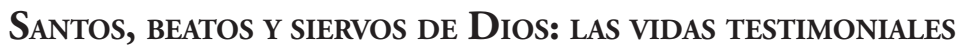

Tienes la obligación de santificarte

Escrivá de Balaguer (1934, p. 191)

Una de las características distintivas del carisma del Opus Dei, es el relativo a su propuesta de santificación. En efecto, posee su propio panteón de seres ejemplares que son recordatorios vívidos de una santidad fundante de la institución ${ }^{14}$ para los miembros. Reflexionando en torno a la construcción de la memoria comunitaria, Giménez Béliveau (2016) indica que la misma refiere a la representación de sí e implica una afirmación de la identidad "haciendo comunidad". Al mismo tiempo, otorga legitimidad al interior de la Iglesia insertando al grupo en un "linaje de creyentes" - en términos de Hevieu-Léger (1993) - y proyectándolo hacia el futuro. Giménez Béliveau especifica que "las comunidades proponen estructuras de funcionamiento compuestas por 'lugares sociales': espacios destinados a los líderes, espacios reservados a los 'virtuosos' [...] y lugares más abiertos, menos regulados" (2016, p. 336). Justamente, la Prelatura parecería contar con casos testimoniales para cada uno de los "lugares sociales" posibles. Así, puede verse que la composición del panteón referido es considerablemente

\footnotetext{
${ }^{13}$ Ver más en: https://opusdei.org/es-ar/article/estatutos-del-opus-dei/. Acceso en: 29 oct. 2019. ${ }^{14}$ Ver más en: https://opusdei.org/es-ar/section/causas-de-canonizacion/. Acceso en: 29 oct. 2019.
}

Debates do NER, Porto Alegre, ANo 2I, N. 4O, P. 4I 5-446, Ago./Dez. 202 I 
diversa: está integrado por una numeraria auxiliar, el fundador de la Obra ${ }^{15}$, su sucesor, obispos, matrimonios, jóvenes, profesionales de las más variadas ocupaciones, etc. Un santo, dos beatos, dos siervos de Dios y once procesos de canonización en curso.

Los individuos ejemplares son aquellas que, citando a Dullo (2011), "son como se debería ser" según los parámetros institucionales, por lo que la exposición de los individuos ejemplares - o su presentación en este caso tendría un carácter pedagógico. Habría entonces vidas testimoniales concretas que permitirían entender la opción que la Prelatura propone como real y asequible a cualquier persona: a saber, todos están llamados a ser santos, cada uno desde su lugar y a través de las circunstancias y actuaciones ordinarias de la vida y del trabajo "bien hecho". Efectivamente, según observan Dias Duarte y Dullo reflexionando en torno a los testimonios, estas opciones de vida expuestas como ejemplares serían "una de las formas constitutivas de la transmisión de la fé cristiana” (2016, p. 12) productoras de efectos sociales. En definitiva, forman a sus fieles indicando la factibilidad que su "espíritu" presenta.

Estudios como el de Menezes (2004) abordan la figura del santo como mediador entre el plano terrenal y el celestial. Otros trabajos, como el de Ferrero (2002), la entienden como mecanismo institucional para mantener el control territorial, al tiempo que otorgaría poder al grupo específico de devotos. A diferencia de estos enfoques - y en sintonía con la propuesta de Bonfim (2016) que ejemplifica el aspecto ejemplar del testimonio como espacio de información y representación diferente a la función que presenta esta acción en el pentecostalismo - propongo pensarlo como caso testimonial y como ejemplo a seguir, ya que los usos de estas figuras particulares que el Opus Dei hace parecen ir en ese sentido.

15 Según expresa un documento del sitio oficial, habría devenido en santo "no sólo por el fecundo ejemplo de su vida, sino también por el vigor absolutamente singular con que, en profética concordancia con el Concilio Vaticano II, procuró, ya desde los comienzos de su sacerdocio, recordar esa llamada evangélica a todos los cristianos" a la santidad. Ver más en: https://opusdei.org/es-es/article/cronologia-san-josemaria/. Acceso en: 17 sept. 2020.

Debates do NER, Porto Alegre, Ano 2 I, N. 40, P. 4I 5-446, Ago./Dez. 202 I 
El llamado universal a la santidad introducido por Escrivá como opción, fue ratificado por el Concilio Vaticano II (1962-1965). Por ejemplo, el quinto capítulo del documento conciliar Lumen Gentium se denomina justamente "Universal vocación a la santidad en la Iglesia". Allí se afirma que "todos los fieles, de cualquier estado o condición, están llamados a la plenitud de la vida cristiana y a la perfección de la caridad, y esta santidad suscita un nivel de vida más humano incluso en la sociedad terrena" ${ }^{16}$.

También, Juan Pablo II se refirió a la santidad como camino para el laicado. En esta línea, decía en una audiencia general de 1993:

La Iglesia es santa y todos sus miembros están llamados a la santidad. Los laicos participan en la santidad de la Iglesia, al ser miembros con pleno derecho de la comunidad cristiana; y esta participación, que podríamos definir ontológica, en la santidad de la Iglesia, se traduce también para los laicos en un compromiso ético personal de santificación. ${ }^{17}$

Más recientemente, Gaudete et exultate (2018), tercera exhortación apostólica ${ }^{18}$ de Francisco, se subtitula "Sobre el llamado a la santidad en el mundo actual”. Allí el papa señala que,

tenemos la tentación de pensar que la santidad está reservada solo a quienes tienen la posibilidad de tomar distancia de las ocupaciones ordinarias, para dedicar mucho tiempo a la oración. No es así. Todos estamos llamados a ser santos viviendo con amor y ofreciendo el propio testimonio en las ocupaciones de cada día, allí donde cada uno se encuentra ${ }^{19}$.

${ }^{16}$ Ver más en: http://www.vatican.va/archive/hist_councils/ii_vatican_council/documents/ vat-ii_const_19641121_lumen-gentium_sp.html. Acceso en: 17 de sept. 2020.

17 Ver más en: http://www.vatican.va/content/john-paul-ii/es/audiences/1993/documents/ hf_jp-ii_aud_19931124.html. Acceso en: 17 sept. 2020.

${ }^{18}$ Instrumentos de carácter teológico de carácter exhortativo que normalmente se utiliza para expresar las conclusiones más importantes de un sínodo de obispos (en comunicación personal con el Dr. Astigueta SJ).

19 Ver más en: http://www.vatican.va/content/francesco/es/apost_exhortations/documents/papa-francesco_esortazione-ap_20180319_gaudete-et-exsultate.html. Acceso en: 17 sept. 2020.

Debates do NER, Porto Alegre, ANo 2 I, N. 40, P. 4I 5-446, Ago./Dez. 202 I 
En el sitio oficial de la Obra se pueden encontrar referencias a dicha exhortación que manifiestan reconocer en ella el carisma de la Prelatura. Entre otras cosas, el documento inspiró una conferencia llevada a cabo en la Universidad Católica Argentina y organizada por el Opus Dei en colaboración con más instituciones. La invitación que recibí por mail decía:

A partir de la publicación del documento Gaudete et Exsultate (2018), el Papa Francisco plantea la santidad como un programa de vida para el hombre actual. Hay entre nosotros modelos creíbles de santidad que nos muestran que es posible.

En éste espíritu y adhiriendo a la moción del Santo Padre, hemos diseñado un itinerario de conferencias que presentamos bajo la modalidad de "diálogos" donde es nuestra intención profundizar sobre la vida de personas que, con distintas vocaciones, representan vidas y modelos creíbles de coherencia en el seguimiento de Cristo, el Evangelio y de fidelidad a la Iglesia ${ }^{20}$.

Vía WhatsApp el texto era más breve e informal y versaba: "Aspirar a la santidad no es tener una vida de superhéroe, sino vivir con Amor las cosas sencillas de todos los días y comunicar esa alegría a los demás”. Junto que los diversos "testimonios de santidad" expuestos, incluía el de la Beata Guadalupe Ortiz de Landázuri, una mujer laica perteneciente al Opus Dei quien según expresa la página web apuntó a "la profesionalidad en los diversos trabajos que empeño" 21 .

Los casos ejemplares y los testimonios forman parte de la dinámica de las actividades que el Opus Dei realiza regularmente. Como señala Teixeira (2016, p. $108)$ siguiendo a Dullo $(2011,2013)$ la ejemplaridad de las trayectorias singulares posee un potencial pedagógico que se vuelca en la narrativa testimonial. Así sucede en los eventos de recaudación de fondos a los que concurrí durante el trabajo de campo que se abordará en el siguiente apartado. Allí, algunas estudiantes del colegio al cual se reserva el dinero recolectado - y que poseen trayectorias

${ }^{20}$ Ver más en: http://uca.edu.ar/es/inscripcion-santidad-una-propuesta-para-el-mundo-de-hoy. Acceso en: 17 sept. 2020.

${ }^{21}$ Ver más en: https://opusdei.org/es-ar/section/causas-de-canonizacion/. Acceso en: 30 sept. 2021. 
destacables según el personal de la institución y las organizadoras del encuentro -, dan su testimonio y comentan logros que son luego celebrados por las asistentes. Lo mismo acontece en las charlas de formación política que se imparten en el marco de otra de las iniciativas solidarias que la Obra ofrece - y que analizaré en el último apartado. En ellas se busca inspirar a las jóvenes que allí concurren a través de la reflexión sobre los ejemplos de mujeres "comprometidas". En este sentido, expresan ejemplos destacables en tanto se considera que se desempeñan correctamente en sus ocupaciones diarias que son la vía posible a la santidad. Efectivamente, según rescatan Dias Duarte y Dullo (2016), el testimonio en el cristianismo se relaciona con la idea de conversión y la de salvación, siendo en este caso una intención clara demostrar las posibilidades de alcanzar la santidad - es decir salvarse - siguiendo la propuesta del carisma de la Obra. A su vez, los testimonios de santidad corriente o los casos exitosos que se rescatan en las diversas actividades a las que concurrí, reactualizan y mantienen vivo el espíritu de la Prelatura, evidenciando que la santidad es alcanzable a través de ejemplos cercanos, concretos y reales. A diferencia de Bispo (2021, p. 25) que atribuye lo testimonial a ejemplos de oposición al mundo secular, el Opus Dei aspira a la inserción en el mundo para la propia santificación y la santificación del entorno. Lo mismo reconoce Dullo quien refiere a la existencia de un "proceso de mundanización del catolicismo resultante en un secularidad singular” (2016, p. 86), la secularidad católica.

\section{FORMAR LA SENSIBILIDAD SOCIAL: TESTIMONIOS DE POBRES EJEMPLARES}

Con motivo de mi tesis doctoral asistí a algunos de los eventos caritativos en los que se expusieron casos testimoniales de estudiantes ejemplares ${ }^{22}$ que

${ }^{22}$ A diferencia de lo que se reconoce para el caso del pentecostalismo (Bispo, 2021, p. 27), el testimonio no está a cargo de conversas o de personas que hayan tenido y superado obstáculos personales, pero sí estructurales reconociendo el mérito individual por no haber llegado a incurrir en acciones consideradas condenables.

Debates do NER, Porto Alegre, ANo 2 I, N. 40, P. 4I 5-446, Ago./Dez. 202 I 
asistían al colegio beneficiado, el Buen Consejo, perteneciente a AESES (Asociación de Emprendimientos Sociales, Educativos y de la Salud) ${ }^{23}$.

Según me comentaba una integrante del equipo directivo, las familias de "bajos recursos" - mayoría en la institución - se caracterizarían por proporcionar entornos que sitúan a los chicos en el mundo adulto a temprana edad, sea por contacto con formas de autoridad violenta, "la sensualidad" o por llevarlos a cumplir con funciones de cuidado de menores. Se busca, por ende, que el estudiantado pueda transitar la etapa de la niñez formándose para la posterior inserción en la sociedad. Esto serviría para que no desarrollen prácticas condenables como la delincuencia o el consumo problemático de sustancias, a causa del pronto y disruptivo acceso a "cosas que ni siquiera un adulto vio en su vida" 24 . Resaltando la eficacia de la propuesta educativa - en parte atribuída a la educación diferenciada que potenciaría "lo que es femenino" - me explicaba que el 90\% de las casi mil cuatrocientas "chicas que tienen" en el colegio, continúa su formación una vez concluida la escolaridad, tornándose "mujeres fuertes, bravas, que se llevan el mundo por delante”.

En esta dirección, una de las integrantes de la Asociación de Amigos del Buen Consejo o Patronato - que se encarga de la recaudación de fondos para el mantenimiento edilicio de la institución - reconoció la importancia del ejemplo que sienta el "progreso" de las egresadas, el "ver que su vecina se recibió de arquitecta y salió de la villa con toda su familia”. Siguiendo a Texeira (2016), podría señalarse que "dar testimonio" de una recuperación moral y ser consciente de la seriedad de la práctica y la responsabilidad que

${ }^{23}$ Organización sin fines de lucro que gestiona los colegios Cruz del Sur y Buen Consejo, instituciones que tienen "como objetivo la inclusión en el sistema educativo de niñas y niños de escasos recursos, integrando a las familias y a las diversas comunidades locales: religiosas, civiles y sociales". Ver más en http://www.buenconsejo.edu.ar/acerca/. Acceso en: 2 marzo 2021. Al igual que otras asociaciones civiles con las que tuve contacto durante mi trabajo de campo, está inspirada e íntimamente ligada al Opus Dei aunque sin pertenecer directamente a la Prelatura.

${ }^{24}$ Entrevista realizada a la representante de AESES en el Colegio del Buen Consejo en Barracas el lunes 14 de mayo de 2018. 
deriva de ello hace que la persona "sea testimonio" para los demás. Con esa intención es que se "empapelan los pasillos del colegio con frases del tipo: 'todas somos iguales, todas podemos, todas tenemos las mismas oportunidades". Además, sostuvo que,

ellas tienen que entender que tienen que tener las mismas... o sea que se merecen y que tienen que tener las mismas oportunidades que cualquiera. Eso creo que es lo que más nos preocupa a todas. Desde la autoestima, pero sobre todo realmente que lo entiendan. O sea que si ellas lo buscan lo van a conseguir y que vamos a estar todas para ayudar en ese punto, ¿no? Hay historias muy fuertes ahí adentro, hay chicas que no quieren volver a su casa porque escuchan tiros, porque la pasan muy mal [...]. Eso por ahí a mí es lo que más importa, que ellas realmente se den cuenta que pueden tener las mismas oportunidades dentro de todo, ¿no? Dentro de sus capacidades también, si las buscan las pueden lograr, la realidad es esa. Favaloro salió de una villa de Rosario. Se puede ${ }^{25}$.

Es visible la valorización que hay del mérito y el esfuerzo, por momentos minimizando la posible incidencia de las condiciones estructurales o la misma situación contextual de la persona. En parte sus "logros" son vinculados al aprovechamiento de oportunidades individuales, oportunidades que les son ofrecidas y se presentan como mejores que otras opciones de ayuda existentes. Así, las "jóvenes incluídas" mostrarían el horizonte de expectativas (Dullo, 2016).

Boltanski (1999) caracteriza a las "políticas de piedad" como aquellas que no piensan si el caso que abordan es justo - esto se relaciona con la falta de cuestionamiento a las estructuras productoras de desigualdad mencionada - y lo "híper-singularizan", aunque dejan lugar a pensar que el afectado podría ser otro. La híper-singularización es visible en los eventos de recaudación de fondos que la Asociación de Amigos del Buen Consejo lleva a cabo. Allí se brindan testimonios por parte de exalumnas y alumnas

${ }^{25}$ Entrevista realizada a una de las integrantes del Patronato en el barrio de Recoleta el lunes 18 de junio de 2018.

Debates do NER, Porto Alegre, ANo 2 I, N. 4O, P. 4I 5-446, Ago./DeZ. 202 I 
prontas a finalizar sus estudios secundarios. Si bien ellas relataban sus historias (exitosas) personales, podría inferirse que lo mismo sucedía con sus compañeras. Dullo (2016) observa que en los testimonios de "jóvenes incluídos" de un centro de promoción social católico, no se puede distinguir la temporalidad individual, asemejándose la trayectoria de quien expone a la de la audiencia, "uniendolos en un sujeto colectivo que participa del proceso de transformación y ruptura, instaurando en los oyentes la ampliación de los horizontes de posibilidad" (Dullo, 2016, p. 100, traducción nuestra). De hecho, estas exposiciones suelen ir acompañadas de las palabras del equipo directivo que brinda datos estadísticos para complementar el relato: cerca del $60 \%$ de las estudiantes provienen de la villa 21-24 o barrios aledaños, y aproximadamente el $80 \%$ de las egresadas siguen formándose a nivel terciario o universitario (muchas de ellas con becas en universidades privadas). Continuando con Boltanski (1999), el acto de dar dinero - la finalidad concreta de estos espacios- constituye un lazo mínimo y abstracto que permitiría contrarrestar la culpa que produce la desigualdad.

Los elementos que observan como característicos a la población del colegio y los casos "ejemplares" que reflejan los ideales (mujeres fuertes y femeninas) y valores que rescatan (mérito y esfuerzo), son presentados en los eventos para formar a quienes allí asisten en la sensibilidad social. En su trabajo sobre las voluntarias de Cáritas, Zapata (2005) retoma a Guber (1998) para afirmar que existen maneras legítimas de narrar experiencias en el proceso por asumir identidades sociales. Asimismo, refiere a Lutz y Abu-Lughod (1990) quienes señalan que los discursos emotivos y los discursos sobre las emociones ordenan jerárquicamente a los grupos sociales y determinan una manera de experimentar las relaciones sociales, es decir, que producen orden social y dan significado sociocultural y emotivo al mismo. Zapata expresa, siguiendo a las autoras, que "las emociones pueden ser generadas por tipos especiales de eventos sociales de los que determinados grupos pueden ser excluidos, por lo cual también pueden ser inhibidos de tener ciertas experiencias emocionales" (2005, p. 109). La producción de la sensibilidad social en las mujeres que concurren a los eventos está a cargo 
de las jóvenes ejemplares. Como nota Martins (2016), una característica central de las políticas de piedad consiste en distinguir quién sufre de quién observa ese sufrimiento. Siguiendo a Boltanski (1999) afirma que quien no sufre puede ayudar al que sí.

Así, en una oportunidad, las integrantes del Patronato le pidieron a la directora de primaria del colegio si les podía "conseguir esta chica que es un amor, es una genia”, a quien habían visto hablar muchas veces sobre su trayectoria y "siempre colabora". Al respecto, Dullo reconstruye la siguiente tensión,

Bourdieu enfatiza que aquel que realiza el acto de habla precisa ser autorizado a hablar, al tiempo que Butler enfatiza la potencialidad que el sujeto tiene de hablar con autoridad, mismo sin haber sido autorizado socialmente [...] el acto de habla dependería de la posición social del enunciador y sería autorizada en la medida en que el agente incorpore el habitus de aquel campo por medio de una serie de prácticas miméticas, terminando por reproducir el status quo [...]. Es esencial que el testimoniante posea legitimidad para que su discurso sea eficaz, mas esa legitimidad no proviene de una atribución hecha por otro sujeto, sino de la relación entre su trayectoria y la de quienes lo oyen (Dullo, 2016, p. 99, traducción nuestra).

Efectivamente, la exalumna aceptó la invitación al evento que se haría en el Jockey $\mathrm{Club}^{26}$ para contar su historia. De esta manera, después de que el equipo directivo hiciera una breve presentación de la institución, la joven comenzó saludando a quienes estaban presentes: "Buenas noches a todos y - sobre todo - todas, porque veo que son más señoras, muy lindas". Agradeció, en primer lugar, que se hubiesen "levantado para venir", que estuvieran allí y que "ayuden tanto". Contó que se encontraba cursando tercer año de contabilidad en "la [Universidad] Católica". Explicó que es de la villa 21-24 y que su mamá es empleada doméstica y su papá albañil, "por ende, no finalizaron sus estudios secundarios”. Dijo que gracias al colegio ella estaba en la

${ }^{26}$ Relato construido a partir de un fragmento de nota de campo del evento de recaudación de fondos llevado a cabo en el 2017. 
universidad con una beca, y que era una de las tantas chicas con la posibilidad de "cambiar su vida y salir" 27 . Comentó que cuando entró al colegio, el 70\% de las alumnas eran de la villa pero que era más fuerte para ella el contraste de ir desde la villa a la UCA. Las directoras agregaron que cuando llegó al colegio era buena ("eso no es mérito del colegio") pero muy tímida, y que hoy estaba aquí dando testimonio en público ${ }^{28}$. Cuando terminó su discurso, entre los aplausos y el entusiasmo de las presentes, una de las organizadoras del evento le llevó un dije de los que se iban a rifar ese día de regalo.

En esta misma dirección, Dullo (2008), estudiando las acciones de promoción e integración social llevadas a cabo por los maristas en Brasil, sugiere que las mismas ofrecen ejemplos para poner a disposición una imagen que le permita al resto de las personas usar de modelo. De este modo, tornándose verosímiles, aquellas producen una identificación en esos mecanismos de éxito emprendidos por los que triunfaron. Entonces, según Dullo (2008) la lógica del ejemplo demuestra que ante las mismas adversidades hay quienes lo logran. Si bien en los eventos el testimonio no se da a otras estudiantes del Buen Consejo, confirma la viabilidad de la causa con la que se colabora legitimando lógicas y valores. En efecto, Dullo dice que los casos expuestos son "modelos de relativo suceso de la misión de transmisión de valores que componen la visión del mundo” (2008, p. 130, traducción nuestra) de quienes promueven dichas obras.

En un evento de recaudación de fondos en el Club Alemán ${ }^{29}$ que consistió en una tarde de "té y arte", tras el número del coro hubo también un testimonio. Pasaron dos chicas del último año de colegio a contar qué

${ }^{27}$ A nivel local existen figuras míticas que producen identificación nacional por ser historias de superación de la pobreza. Tal es el caso de Maradona, que estudia Alabarces (2006). El futbolista fue expresión de los deseos aspiracionales de ascenso social de gran parte de la población.

${ }^{28}$ Para el caso de un centro católico que se propone la inclusión social de jóvenes, Dullo observa que habría una apropiación de su éxito (2011, p. 106), aspecto también apreciable en el relato aquí presentado.

${ }^{29}$ Relato construido a partir de un fragmento de nota de campo del evento de recaudación de fondos llevado a cabo en el 2018. 
carreras querían cursar una vez concluida la escolaridad. Una había elegido Educación Física y otra Psicología con una beca que le habían conseguido en el Buen Consejo para estudiar en la UADE. Seguidamente hablaron sobre un emprendimiento de confección de almohadones desarrollado en el marco de una materia. Refirieron a tres modelos que fabricaban, uno que venía con una manta, uno que era para que los "más chiquitos" pinten y otro que era decorativo; también conversaron sobre cómo se organizaban, en qué área estaba cada una y anunciaron que habían ganado el concurso de likes de la fundación Junior Achievement. Una docente que se encontraba presente agregó que ésta era una empresa "tipo B". Aprovechando el pie las chicas afirmaron que trataban de dignificar la labor textil empleando a las mujeres del barrio, minimizaron sus ganancias para poder pagar bien (\$20 cada almohadón). Contaron que muchas mamás se dedican al rubro, pero trabajan en muy malas condiciones. Según relataron, a las $2 \mathrm{hs}$ de comunicar su idea ya había una larga fila para las entrevistas en el pasillo de la institución. Por último, dijeron que algunos profesores compraron acciones y obtuvieron ganancias por ello.

A lo largo del testimonio, las "buenas noticias" fueron acompañadas por aplausos y expresiones de asombro por parte de las donantes. Como observa Reinhardt, estos ejemplos "dotan al carisma de cuerpo, estilo y voz, y lo insertan en esqueletos institucionales al animar aún más su reproducción mimética” (2016, p. 64, traducción nuestra). Una vez finalizada la intervención, las mujeres del Patronato me instaron a vender rifas para aprovechar el impacto del relato y obsequiaron unas cremas a las alumnas por su colaboración. Como observa Zapata, Himmelfarb (1991) estudia "la compasión como un sentimiento moral que despierta la miseria" que produce "acciones benevolentes y caritativas de determinados sectores, orientados a hacer progresar moralmente a los pobres y a clasificarlos" (2005, p. 115). Ambos testimonios reflejaban una procedencia específica de "barrio" que se espera que produzcan empatía, para que se colabore en acompañar a las jóvenes en su formación para "salir de la villa y progresar". 
Amado sostiene que el relato testimonial consiste en una "interpretación por la que las acciones privadas se expresan desde la conciencia del marco público donde se inscriben" (2014, p. 512). Por su parte, Altman (2011) centrándose en los evangélicos mocoví, caracteriza al testimonio como una puesta en escena cuya función es socializar a los asistentes en la expresión religiosa y el modo válido de construcción del relato sobre la propia trayectoria. Salvando las distancias, y siendo que las experiencias aquí seleccionadas no derivan en testimonios por parte de las donantes, la elección de las expositoras da cuenta de determinadas nociones y visiones sobre la pobreza. Rescata la dignidad de aquellos "buenos pobres" que se "recuperan moralmente" (Bowen Silva, 2015) aprovechando las oportunidades que le ofrecen y dejándose ayudar.

Se puede notar que las alumnas incorporan los valores y actitudes que se creen positivos o, al menos, son los casos que se eligen mostrar. Justamente, Dullo enumera cuatro aspectos que los “jóvenes incluídos" deben incorporar ${ }^{30}$, algunos de los cuales son aprendidos también por las jóvenes que dan testimonio en estos eventos:

1) una conciencia corporal: toda una corporalidad que no es adecuada más allá de las fronteras de la villa y del entorno y su modificación para la entrada en el mercado de trabajo; 2) maneras más claras de expresión de sí [...] y 4) el incentivo para el término de los estudios de los niveles básicos y medios y el ingreso a la educación superior (Dullo, 2011, p. 111, traducción nuestra).

Habría entonces una suerte de apropiación de los principios que se transmiten a las alumnas en lo discursivo, pero también en tanto que los mismos se traducen en aprendizajes concretos, como el estudio en una universidad privada o el desarrollo de un emprendimiento. Asimismo, las enseñanzas y parámetros morales predicados se visibilizan en marcas y usos del cuerpo y la voz, lo que permite - entre otras cosas - gobernar el "yo" de

${ }^{30}$ Partiendo de Mauss (2003, p. 405-407), Dullo (2011) sugiere que la transformación del comportamiento deriva del reconocimiento de la eficacia de la técnica, cargando su ejecutor de prestigio y autoridad.

Debates do NER, Porto Alegre, ano 2 I, N. 40, P. 4I 5-446, Ago./Dez. 202 I 
la persona (Foucault, 1977). De este modo, se autogestionan y reducen los aspectos que pueden pensarse como potencialmente negativos; esto queda ilustrado paradigmáticamente en el cuidado de "las formas".

La lógica económica a la que parecen suscribir tanto las mujeres caritativas como las jóvenes destinatarias de su mensaje, se percibe en varias de las cuestiones que se remarcaron a lo largo de este apartado. De manera global, ello tiene que ver con concepciones sobre el rol de lo económico en la vida social y sobre la pobreza en sí. Es decir, se aceptaría y apoyaría la inserción de las estudiantes en el modelo económico vigente - que en ningún momento es objeto de cuestionamiento -, por lo que las alumnas del Buen Consejo son percibidas como "bien" formadas a raíz de su compromiso con prácticas y ensayos que fomentan y valoran el espíritu emprendedor y la simulación de las dinámicas empresariales. El testimonio de las estudiantes del último ańo del secundario, por ejemplo, expresa el lugar que se le atribuye al trabajo y cómo es valorada cada tipo de labor. El protagonismo dado a lo profesional se debe a que se concibe como una vía de santidad.

Si bien hay quienes identifican el testimonio con un narración de la historia de vida estructurada en un lenguaje de los sentimientos (Bispo, 2021, p. 25), aquí se apela a la sensibilización del público sin resaltar el sufrimiento propio, proceso que acontece junto con la sociabilidad y el entretenimiento. Tal como reconoce Dullo "los procesos de inclusión social y transformaciones socioculturales son una modalidad de sacralización" (2011, p. 109). Lo mismo se evidencia en estas instancias, siendo que no sólo las jóvenes ejemplares darían testimonio de su formación amplia en pos de la santidad en el trabajo profesional y las circunstancias ordinarias de su vida - tal como indica el carisma de la Obra - sino que las mujeres de la audiencia podrían santificarse en estas actividades cotidianas "desde el lugar donde les toca vivir".

\section{CHARLAS DE FORMACIÓN POLÍTICA: LAS JÓVENES EJEMPLARES}

Impulso Social es un organización perteneciente a ICIED (Iniciativas de Capacitación Integral para Emprendimientos de Desarrollo), otra asociación 
civil vinculada al Opus Dei que apunta a la "capacitación de la mujer"31, para que llegue "a ser un líder positivo en su entorno, y que tenga las herramientas para poder asumir un rol protagónico al servicio de los demás”. Específicamente, Impulso Social se define como "una organización que tiene como objetivo formar en compromiso social a mujeres jóvenes, desarrollando proyectos que combinan acción y reflexión. Trabajan en contextos vulnerables, en red con otras organizaciones" ${ }^{\prime 2}$. El sitio web agrega que coordinan actividades de voluntariado de estudiantes y jóvenes profesionales.

Dentro de los eventos y flyers que se pueden encontrar en la página de Facebook de la organización ${ }^{33}$, se cuentan testimonios de quienes participan en acciones solidarias y sociales, ligadas al cuidado, la salud, la educación o la promoción de "valores" ${ }^{4}$. Muchas de las iniciativas que se presentan, no solo tienen una orientación católica sino que están vinculadas en mayor o menor medida con la Obra. Gran parte de las charlas están a cargo de profesionales o voluntarios que se desempeñan en el tercer sector. Usualmente no aparecen referencias a la política partidaria como espacio de inserción en la

${ }^{31}$ Ver más en: https://www.icied.org/. Acceso en: 6 de jul. 2020.

${ }^{32}$ Ver más en: https://www.icied.org/iniciativas. Acceso en: 6 jul. 2020.

33 Ver más en: https://www.facebook.com/media/set/?vanity=ImpuSocial\&set=a. 520274 288033133. Acceso en: 10 jul. 2020.

${ }^{34}$ Un ejemplo es la invitación de "Grupo Sólido", fundación que promueve la defensa del "valor absoluto de cada persona humana desde su concepción hasta su muerte, y creemos que el desarrollo de la misma se da en las relaciones de amor sano". Ver más en https:/gruposolido.org/quienes-somos/. Acceso en: 11 jul. 2020. Otras organizaciones con las que trabajan son: Más Humanidad (http://www.fundacionmashumanidad.org), CONIN (https://conin.org.ar), Luz de esperanza, Centros de Formación Rural (http:// www.fundacionmarzano.org.ar/), CECAM (https://www.cecampilar.org/), Akamasoa Argentina (http://akamasoaargentina.org/), Casa Ronald McDonald Argentina (https:// www.rmhcamericalatina.org/Casas_Ronald_McDonald_Argentina), Fundación Espartanos (https://www.fundacionespartanos.org), Talleres de Marangatú (https://www.icied. org/iniciativas), Botines Solidarios (https://botines-solidarios.org.ar/), Unidad ProVida (https://www.unidadprovida.org/) o con instituciones como el Hospital Gutiérrez, varios comedores, hospice, la Universidad Austral, entre otras.

Debates do NER, Porto Alegre, Ano 2 I, N. 40, P. 4I 5-446, Ago./Dez. 202 I 
dirección de la "conciencia y el compromiso" que la organización persigue, ni a tendencias político-partidarias explícitas, aunque se tocan temas de actualidad en materia social, política y económica. De hecho, los jóvenes que conforman el tercer sector conciben la política como un espacio de circulación dificultosa, abstracta, poco transparente, dogmática, excesivamente burocrática y donde rigen intereses personales por sobre "las ganas de ayudar" (Beltrán, 2010, p. 78). Todo esto deriva en un descreimiento en la política partidaria, aunque no necesariamente - como indica Sidicaro (2008) - en el sistema democrático, lo que coexiste con una visión más inspirada en un criterio instrumental que la considera necesaria ${ }^{35}$.

A principios de octubre del 2016 al anochecer, concurrí a una charla llevada a cabo en uno de los centros femeninos de la Obra ubicado en Belgrano. La presentadora comenzó informando al público (de casi cincuenta personas, compuesto en su mayoría por mujeres menores de o cercanas a los treinta años) que la organización que promovía este encuentro busca "formar jóvenes para los otros, con compromiso social y que sean parte del

${ }^{35}$ Estudios posteriores a la elección de Mauricio Macri como presidente, complejizan el análisis. Tal es el caso de la investigación de Vommaro (2019) sobre la conformación de Cambiemos en Argentina. Según explica, el fracaso de la política tradicional hizo que "los mejores", es decir, aquellos que provienen de empresas y ONGs, se decidan por "ayudar" desde la organización partidaria. El autor sostiene que este espacio canalizó y tradujo energía y preocupaciones morales en compromiso político, facilitando la realización individual de quienes se implicaron en sus filas mediante la gestión y la entrega de sí (Boltanski y Chiapello, 2002) como don voluntario. Si bien, desde Impulso Social no se fomenta explícitamente la adscripción a partidos políticos específicos, sí se insiste en la participación en la esfera pública de modos diversos. Además, se proponen instancias que, junto con estas charlas de formación política que presento en este apartado, se ofrecen como ámbito donde buscar la santidad mediante la propia entrega. Asimismo, como sentencia Dullo, "para consolidar su condición ejemplar, el joven se debe ofrecer como camino a ser seguido, presentando su experiencia personal [...]. La ejemplaridad aparece, por lo tanto [...] como la cualidad personal de un líder carismático: es él quien, por medio de su liderazgo y de probar su éxito, ofrece bienestar a sus adeptos, uniéndolos en una "relación comunitaria de carácter emocional” (Weber, 2000, p. 159)” (Dullo, 2011, p. 107).

Debates do NER, Porto Alegre, ANo 2 I, N. 4O, P. 4I 5-446, Ago./DeZ. 202 I 
cambio que quieren ver" ${ }^{36}$. El nombre del evento, según informaba la página de Facebook oficial era "Cuba y Venezuela, dos testimonios de jóvenes comprometidas" 37 . Brevemente, aclaraba que "en esta oportunidad vamos a estar escuchando el testimonio de Rosa María Payá (cubana, Presidente de la Red Latinoamericana de Jóvenes por la Democracia) y de Vicky Maneiro (Venezolana, Coordinadora de Control Electoral con SUMATE Zulia en Maracaibo 2011-2015)", y completaba el comunicado con una invitación a "seguirla" con unas empanadas luego del conversatorio. Un link y una dirección de mail finalizaban el comunicado para manejar las inscripciones más prolijamente. Además, introducía a las expositoras a través de sus experiencias de formación universitaria y trabajo como "activistas", del siguiente modo: Zulia en Maracaibo 2011-2015

Rosa Maria Paya Acevedo preside la Red Latinoamericana de Jóvenes por la Democracia presente en 23 países de la región y es directora ejecutiva de La Fundación para la Democracia Panamericana. Trabaja por fomentar la solidaridad internacional con Cuba, y buscar justicia por el asesinato de su padre Oswaldo Payá, premio Sajarov del Parlamento Europeo y 5 veces nominado al Premio Nobel de la Paz. En la actualidad coordina la campaña internacional Cuba Decide, que busca la realización de un plebiscito en favor de las elecciones libres y plurales en Cuba por primera vez en 67 años.

Es licenciada en Física egresada de la Universidad de la Habana, y egresada de la Universidad de Georgetown en Washington DC de los programas: Global Competitive Lidership y Summer Institute on the Constitution. Es activista pro-democracia y ha dirigido actividades de la sociedad civil dentro de Cuba desde el año 2009. Formó parte del Equipo Coordinador del Movimiento Cristiano Liberación (MCL). Se ha desempeñado como miembro del Consejo de Redacción del Somos Liberación, publicación del MCL y fue jefa

${ }^{36}$ El relato está compuesto a partir de la nota de campo del día 11 de octubre de 2016 en un centro de la Obra ubicado en Belgrano, CABA.

37 Ver más en: https://www.facebook.com/events/450699681743630/?post_id=450915 975055334\&view=permalink. Acceso en: 5 abr. 21. 
de sección de la revista católica IXTHYS. Ha participado en diversos foros internacionales desde el 2013 como el Consejo de Derechos Humanos de Naciones Unidas, el Parlamento Europeo, el Senado de los Estados Unidos, la Organización de Estados Americanos, La Cumbre de las Américas y varios parlamentos nacionales.

En cuanto a la otra jóven, la información era más breve y decía:

Victoria Maneiro nos va a estar contando la situación de Venezuela, donde nació y vivió hasta hace un año. Vicky es abogada por la Universidad del Zulia, Venezuela. Desde 2010 que colabora en la transparencia de las elecciones en Maracaibo como coordinadora de control electoral por medio de la Fundación SUMATE Zulia. Encontrala en Twitter cómo @vic_vaporub y vení a escucharla el próximo martes.

Bajo la invitación de Facebook se daban detalles sobre Impulso Social, destacando que había surgido "por iniciativa de universitarias y jóvenes profesionales interesadas en despertar la conciencia y el compromiso social de los jóvenes". Con esa meta se ofrecían actividades de "capacitación y de acción, dos líneas complementarias que garantizan la formación en compromiso social" 38 . Tal vez por su objetivo expreso aquí, y por resaltar el profesionalismo y lo académico, es que los perfiles de quienes hablarían esa noche resaltaban su instrucción universitaria, su participación en organizaciones de la sociedad civil y su activismo político en oposición a los gobiernos nacionales. Así, se mencionaba la cuestión del resguardo de la democracia (junto con conceptos como el de "transparencia" o control electoral), los derechos humanos o el liderazgo, nombrando también los organismos y espacios por los que habían transitado. No es casual que se destaquen estos aspectos, ya que la tendencia es observada por quienes estudian la participación juvenil en las ONGs. En esta dirección, Cerdeira, Faerman y Pahor

${ }^{38}$ Ver más en: https://www.facebook.com/events/450699681743630/?post_id=450915 975055334\&view=permalink. Acceso en: 5 abr. 21. Utiliza el masculino, aunque la propuesta apunta únicamente a mujeres.

Debates do NER, Porto Alegre, ANo 2I, N. 4O, P. 4I 5-446, Ago./DeZ. 202 I 
(2010) señalan que "como característica propia del modelo liberal, el rol del profesional experto, con sus opiniones fundadas en el conocimiento y sus diagnósticos certeros, adquiere más importancia en el imaginario social y, por consiguiente, mayor centralidad en el espacio político” (2010, p. 114). Asimismo, como mencioné anteriormente, la postura en relación a la política es ambigua y algo tensa, reconociendo su importancia y sin oponerse al sistema de representación partidaria pero sin identificarse con él.

Durante el conversatorio, ambas jóvenes refirieron a la situación de sus respectivos países como similar al último gobierno de facto argentino: como un contexto de violación de los derechos humanos y falta de democracia, así como tensiones sociales, represión y excesos cometidos por parte de las fuerzas de seguridad. Pero junto con la "cultura del miedo" que nombró la joven cubana, este poder se sostendría por ser paternalista (hablaron también de los planes sociales) y generar dependencia. En este sentido es que las dos se encontraban involucradas en iniciativas impulsadas por sectores disidentes dentro de la sociedad civil en defensa de "la libertad". La traducción concreta de este valor sería, por un lado, "la democracia" y, por el otro, una oposición a modelos económicos de mayor regulación e incluso un apoyo a un viraje hacia el capitalismo (visible al identificar que el "temor al capitalismo feroz" deriva de los "miedos producto de la incomunicación”, y aclarando que dicho sistema brindaría "posibilidades de mejor salud y economía”). Los gobiernos anti-democráticos que coartan libertades o derechos individuales se alejan de modelos económicos como el capitalismo y de los principios que operan en él: la idea de libertad de la persona, el valor del esfuerzo personal y el mérito.

Al investigar a las elites católicas chilenas, Thumala Olave (2010) identifica discursos que colocan al capitalismo democrático como el modelo indicado para la erradicación de la pobreza, por permitir a los individuos desarrollar al máximo su potencial en tanto promueve principios como el de la propiedad privada y el esfuerzo personal. Afirma que la idea de "la santificación en la vida ordinaria que surgió con el Concilio Vaticano II implica un pasaje hacia la conceptualización positiva de los negocios y la creación de ganancias" (Thumala 
Olave, 2010, p. 15, traducción nuestra), y observa que esto es característico del carisma del Opus Dei en particular. Por su lado, Muehlebach señala que "la doctrina social de la Iglesia y el post consenso de Washington [...] proponen teorías sobre la sociedad y la economía que tienden a dejar las bases estructurales del neoliberalismo intactas" (2013, p. 461, traducción nuestra). En tal dirección, la elección de la temática de la charla y de las expositoras reflejan las líneas que en las que se busca formar a las jóvenes asistentes, en especial, en cuanto a una postura político-económica que se condice con una tendencia específica al interior de la Iglesia y de la Prelatura en particular. En efecto, Dias Duarte y Dullo entienden al testimonio como "acto performativo en que se moviliza la experiencia vivida, su transformación en narrativa, y aún la relación con la audiencia que escucha y sufre los objetivos o sus efectos concretos de su práctica” (2016, p. 15). Concretamente, en el relato citado en este apartado puede verse un vínculo claro entre la experiencia personal de las jóvenes invitadas a hablar, y una de las posibilidades que el carisma del Opus Dei propone para lograr la santidad. A saber, el ejercicio del trabajo profesional como circunstancia ordinaria de la vida y en el "lugar donde toque vivir".

\section{Conclusión}

Muchas de las actividades de las cuales participé presentan casos ejemplares que dan testimonio de lo que sería el "hacer bien" el trabajo personal. Al igual que lo observado por Dullo (2011), son quienes "son como deberían ser” según los parámetros institucionales religiosos, siendo reproductores del mensaje de salvación (más específicamente de santidad según el Opus Dei). Esto, junto con el panteón de siervos de Dios, beatos y santos de composición diversa que la Obra posee, demuestra que la opción por la santidad es una opción posible sea cual sea la condición de cada uno. Al mismo tiempo, los miembros de la Prelatura refuerzan su creencia en la propuesta de Escrivá, al contar con la "confirmación" canónica por parte de la jerarquía eclesial a través de documentos y discursos conciliares y posconciliares. 
En el caso de los eventos de recaudación de fondos, las colaboradoras promueven las asistentes una sensibilidad social, a través de la exposición testimonial de la realidad de la pobreza desde ejemplos puntuales, singularizados pero generalizables. Según presenté, los testimonios son cristalizaciones discursivas con un alto componente emocional a cargo de personas selectas que pretenden dar sentido, a partir de experiencias de primera mano, a determinado orden socioeconómico. En otras palabras, dichos testimonios consisten en la puesta en escena en un marco particular para socializar a las presentes en cuanto a cómo pensar, sentir y observar la pobreza. Tácitamente, tales elocuciones expresan visiones que colocan al pobre en una posición moral inferior - lo cual aparece en los discursos que traje a colación en el último apartado -, por lo que se los forma (de manera específica y diferente a lo que se hace con quienes no son concebidos así) para que logren superar dicha situación. De hecho, el "buen pobre" (quien aprovecha lo que se le ofrece) condensa y refleja los objetivos alcanzados del proyecto financiado. Así como Teixeira Pinheiro (2016, p. 108) nota, el testimonio actúa como signo de recuperación moral evidenciando lo testimoniable y produciendo al recuperado (o "buen pobre"), según la capacidad del actor y de la institución en que se encuentra. A su vez, estas historias de vida demuestran y reafirman el rol del esfuerzo personal, el mérito y el espíritu emprendedor de la persona. Tales elementos son centrales para capitalizar la oportunidad que brinda la institución. Las jóvenes que dan testimonio en los eventos son, justamente, aquellas que logran apropiarse de hábitos que las colaboradoras identifican como positivos; por ejemplo, su formación académica para insertarse en el mercado laboral que, entre otras cosas, se relaciona con la vía de santificación que el carisma del Opus Dei propone. Mediante la producción de la compasión que los modelos de superación expuestos exhiben, se busca generar una empatía que impulse la acción de dar en pos del progreso moral del pobre en vez de quedarse "encerradas en su mundo".

Para las jóvenes que dan testimonio se trata en parte de contrarrestar las marcas que podrían ser asociadas a una procedencia de clase particular. Efectivamente, al matizar dichas marcas de pertenencia logran insertarse 
en espacios que usualmente les serían vedados: primordialmente, acceden a empresas donde consiguen realizar pasantías por medio del Buen Consejo, y obtienen becas en universidades privadas donde cursan estudios de formación superior. En relación con estos resultados, estas acciones serían concretamente eficientes y, evidentemente, tendrían una pretensión de utilidad, una intención de domesticar el cuerpo social transmitiendo valores civilizatorios. Esto en tanto habría un control cotidiano y una administración del comportamiento para normalizar aquello que representaría una dificultad para que las estudiantes puedan integrarse "al sistema". Además, se apunta a que las propias beneficiadas sean protagonistas de su propio "progreso" y puedan "salir de la villa".

Los casos ejemplares son estimulados como testimonio de lo que entienden como un "buen pobre" y son "presentados en sociedad". El buen pobre es quien se deja ayudar mostrando receptividad a las enseńanzas y docilidad a la conversión, entrando entonces en un proceso de recuperación moral. En suma, es aquél que se apropia de valores (como el éxito personal, el orden, el estudio o la inserción laboral) y conductas (la adaptación específica cristiana y el comportamiento secular que apunta a la santidad en medio del mundo), y que en definitiva logra controlar su yo a partir de una disciplina aprendida en las plataformas que suministran las diferentes obras del Opus Dei.

Parte del proceso formativo que propone Impulso Social incluye momentos de reflexión para lograr mayor profundidad y calidad en el desarrollo de las tareas. Usualmente, estos espacios exponen casos ejemplares de jóvenes con compromiso académico, social o político. Tal es el caso del conversatorio a cargo profesionales o voluntarias de ONGs o iniciativas políticas (en general no partidarias) como el que traje a colación. Las temáticas que se abordan evidencian posturas claras relativas a la realidad social y la economía. Allí se resalta la ejemplaridad de quienes exponen, atendiendo a su formación universitaria y académica (dando cuenta así del valor del "saber experto"), su activismo, su rol en el tercer sector y en espacios de participación ciudadana se rescatan aspectos como el liderazgo, 
la defensa de la democracia y los derechos humanos. Asimismo, no muestran un cuestionamiento al sistema, sino que presentan al capitalismo como modelo adecuado para luchar contra la pobreza, por permitir que los individuos desplieguen su potencial, se esfuercen y ganen lo merecido. Dichos testimonios pueden pensarse como performances para socializar a las jóvenes en la construcción del relato de la experiencia vital (Altman, 2011) - o directamente para "transformarlas" - y transmitir valores relacionados con el carisma del Opus Dei.

En síntesis, la funcionalidad del testimonio y la exposición de casos ejemplares (sean aquellos que oficialmente se encuentran en proceso de canonización o de jóvenes comprometidas y "buenas pobres"), además de formar a quienes reciben sus charlas o conocen sus vidas en la sensibilidad social, socializan a los asistentes en los valores del propio grupo e indican el modo válido de construcción de la propia historia. Si bien autores como Bispo (2021, p. 27) entienden que el testimonio se utiliza para dar cuenta de la fidelidad religiosa ante pares, en los casos aquí tomados se puede ver que la exposición no es necesariamente interna ni se expresa en términos religiosos, aunque puede servir para difundir principios característicos del "espìritu" de la Obra. Es decir, son medios para la propagación del mensaje, la "transmisión de valores" y la "reproducción de la fe" (Rosas, 2013), aunque sin alusión explícita a lo religioso. Pero además, y principalmente, demuestran la posibilidad de santificación en el lugar "donde toque vivir" y realizando las labores ordinarias propias "de manera humanamente perfecta" como posible y alcanzable a través de ejemplos cercanos, concretos y reales que reactualizan el carisma de la Prelatura. 


\section{REFERENCIAS}

ALABARCES, Pablo. El mito de Maradona o la superación del peronismo por otros medios. DeSignis: Mitos y ritos en las sociedades contemporáneas, n. 9, p. 211-220, 2006.

ALTMAN, Agustina. Historia y conversión: el evangelio entre los mocoví del Chaco Austral. RUNA: Archivo para las Ciencias del Hombre, Buenos Aires, v. 32, n. 2, p. 127-143, 2011.

AMADO, Ana María. El testimonio. Voces íntimas en la memoria social. Buenos Aires: CAIA, 2014. p. 512-524.

BELTRÁN, Gastón. La sociedad civil organizada y los jóvenes. Una aproximación a las ONGs y las formas de participación juvenil. In: BELTRÁN, Gastón; ORTEGUI, Romina Mlagamba (org.). Jóvenes y ONGs, una agenda pendiente. Buenos Aires: Aurelia Rivera, 2010. p. 55-90.

BISPO, Raphael. O juízo da fama: moralidades e emoções nas narrativas testemunhais de conversão no mundo artístico evangélico. Religiäo \& Sociedade, São Paulo, v. 41, p. 23-47, 2021.

BOWEN SILVA, Sofía. Educar la moral del pobre: fronteras simbólicas y gobierno de los pobres por parte de la elite económica católica de Santiago de Chile. Pro-Posiçốes, Campinas, v. 26, n. 2, p. 51-73, 2015.

BOLTANSKI, Luk. Distant Suffering: Morality, Media and Politics. Cambridge: Cambridge University Press, 1999.

BOLTANSKI, Luk; CHIAPELLO, Éve. El nuevo espiritu del capitalismo. v. 13. Ediciones Akal, 2002.

BONFIM, Evandro de Sousa. Das relaçóes entre exemplo e parresia: formas de evangelizaçáo católica. Religião \& Sociedade, São Paulo, v. 36, n. 2, p. 71-84, 2016.

CERDEIRA, Mariana; FERMAN, Pablo; PAHOR, Mariana. Percepiones sobre la participacion en la sociedad civil. Las ONGs como ámbito de desarrollo profesional. In: BELTRÁN, Gastón; OTEGUI, Romina Malagamba (org.). Jóvenes y ONGs, una agenda pendiente. Buenos Aires: Aurelia Rivera, 2010. p. 113-132. 
DUARTE, Luiz Fernando Dias; DULLO, Eduardo. Introdução ao dossiê Testemunho. Religião \& Sociedade, São Paulo, v. 36, n. 2, p. 12-18, 2016. DULLO, Eduardo. Políticas de Inclusão e de Salvação: transmissão, transformação e aprendizado de uma visão de mundo cristã e cidadã. 2008. Dissertação (Mestrado em Antropologia Social) - Faculdade de Antropologia, Universidade Federal do Rio de Janeiro, Rio de Janeiro, 2008.

DULLO, Eduardo. Uma pedagogia da exemplaridade: a dádiva cristã como gratuidade. Religiäo \& Sociedade, Sáo Paulo, v. 31, n. 2, p. 105-129, 2011. DULLO, Eduardo. A produção de subjetividades democráticas e a formação do secular no Brasil a partir da pedagogia de Paulo Freire. 2013. Tese (Doutorado em Antropologia Social) - Faculdade de Antropologia, Universidade Federal do Rio de Janeiro, Rio de Janeiro, 2013.

DULLO, Eduardo. Testemunho: cristão e secular. Religião \& Sociedade, São Paulo, v. 36, n. 2, p. 85-106, 2016.

ESCRIVÁ DE BALAGUER, Josemaría. Camino. España, 1934.

FERRERO, Mario. Competition for sainthood and the millennial church. Kyklos, v. 55, n. 3, P. 335-360, 2002.

FERRO, Mario. Competition for sainthood and the millennial church. Kyklos, v. 55, n. 3, p. 335-360, 2002.

FOUCAULT, Michel. Historia de la medicalización. Educación médica y salud, Washington, v. 11, n. 1 p. 3-25, 1977.

GESSAGHI, Victoria. "Ser sencillo, ser buena persona": clasificaciones morales y procesos de distinción en las experiencias educativas de la "clase alta” argentina. Pro-Posiçōes, Campinas, v. 26, n. 2, p. 33-50, 2015.

GIMÉNEZ BÉLIVEAU, Verónica. Católicos militantes: sujeto, comunidad e institución en la Argentina. Buenos Aires: Eudeba, 2016.

GUBER, Rosana. "Truchos y genuinos". Las identidades en el trabajo de campo. Cuadernos de Epistemología, Colômbia, n. 4, p. 23-38, 1998. 
HERVIEU-LÉGER, Danièle. La religion pour mémoire. França: Éd. du Cerf, 1993.

HIMMELFARB, Gertrude. Poverty and compassion. The Moral Imagination of the Late Victorians. New York: Vintage Books. A Division of Random House, 1991.

LUTZ, Catherine; ABU-LUGHOD, Lila. Language and the politics of emotion. Cambridge: Cambridge University Press, 1990.

MARTINS, Isis Ribeiro. Moralidades e atos de fala em serviços de apoio emocional: modalidades laicas da confissão e do testemunho? Religião \& Sociedade, São Paulo, v. 36, p. 19-43, 2016.

MAUSS, Marcel. As técnicas corporais. In: MAUSS, Marcel. Sociologia e antropologia. São Paulo: Cosac \& Naify, 2003.

MENEZES, Renata de Castro. A dinâmica do sagrado: rituais, sociabilidade e santidate num convento do Rio de Janeiro. v. 31. Rio de Janeiro: Relume Dumará, 2004.

MUEHLEBACH, Andrea. The catholicization of neoliberalism: On love and welfare in Lombardy, Italy. American Anthropologist, United States, v. 115, n. 3, p. 452-465, 2013.

REINHARDT, Bruno. De epifania a método: a teopolítica do testemunho em um seminário pentecostal em Gana. Religiāo \& Sociedade, São Paulo, v. 36, p. 44-70, 2016.

ROSAS, Nina. Religiáo, mídia e produção fonográfica: o Diante do Trono e as disputas com a Igreja Universal. Religiäo \& Sociedade, São Paulo v. 33, n. 1, p. 167-194, 2013.

SIDICARO, Ricardo. La pérdida de legitimidad de los partidos políticos argentinos. Temas y Debates, n. 16, p. 29-47, 2008.

TEIXEIRA, Cesar Pinheiro. O testemunho e a produção de valor moral: observaçóes etnográficas sobre um centro de recuperação evangélico. Religiāo \& Sociedade, São Paulo, v. 36, p. 107-134, 2016. 
THUMALA OLAVE, Angélica. The richness of ordinary life: Religious justification among Chile's business elite. Revista Ciencias sociales y religión, Campinas, v. 40, n. 1, p. 14-26, 2010.

VOMMARO, Gabriel. La larga marcha de Cambiemos: la construcción silenciosa de un proyecto de poder. Buenos Aires: Siglo XXI, 2019.

WEBER, Max. Economia e sociedade: fundamentos da sociologia compreensiva. Brasília, DF: Editora de Universidade de Brasilia, 2000.

ZAPATA, Laura. La mano que acaricia la pobreza: etnografía del voluntariado católico. Buenos Aires: Antropofagia, 2005.

Recebido em: 01/10/2021

Aprovado em: 23/11/2021 